\title{
Pyrolysis of cyclo-aromatic diesters
}

\author{
Marta Worzakowska
}

Received: 4 April 2014/ Accepted: 7 July 2014/Published online: 24 August 2014

(C) The Author(s) 2014. This article is published with open access at Springerlink.com

\begin{abstract}
Studies on the pyrolysis of cyclo-aromatic diesters derivatives of 3-phenylprop-2-en-1-ol are presented. The diesters are obtained during catalyzed esterification process of a stoichiometric ratio of 3-phenylprop-2-en-1-ol with suitable cycloaliphatic or aromatic acid anhydride in the solvent-free medium. As an acid anhydrides cyclohexane-1, 2-dicarboxylic anhydride, cis-4-cyclohexene-1,2-dicarboxylic anhydride, bicyclo[2.2.1]-5-heptene-2,3-dicarboxylic anhydride, and phthalic anhydride were applied. The thermal properties of obtained compounds under inert atmosphere were tested by means of differential scanning calorimetry and thermogravimetry coupled with FTIR analysis. The pyrolysis products were determined and the probable mechanism of their decomposition was proposed.
\end{abstract}

Keywords Esterification · 3-Phenylprop-2-en-1-ol · Pyrolysis · DSC · TG/FTIR

\section{Introduction}

Thermogravimetric analysis is one of the most useful techniques of thermal analysis. It is commonly applied to characterize the thermal behavior of various compounds. This technique measures the mass loss as a function of temperature or time. It allows understanding the thermal degradation pathways and degradation kinetics of polymers, organic or inorganic compounds [1-7]. Also, it

M. Worzakowska ( $\square)$

Department of Polymer Chemistry, Faculty of Chemistry, Maria

Curie-Skłodowska University, Gliniana 33 Street,

20-614 Lublin, Poland

e-mail: marta.worzakowska@ poczta.umcs.lublin.pl makes it possible to study the evaporation process, product and component stability, and changes in component properties during heating in inert or oxidative atmospheres, which is a necessary knowledge in order to find the practical applications of many compounds. In addition, the TG coupled to FTIR or QMS allows identifying the compounds which are released during decomposition or degradation process of studied materials. It can be useful in characterization of the decomposition and thermal degradation mechanism of polymers, copolymers, inorganic and organic compounds [8-13], oxidation of materials [14-18], and in estimation of possible air pollution during manufacturing the materials in high temperatures.

In our previous papers, we have used the techniques of thermal analysis coupled to FTIR or/and QMS to study the degradation mechanism under pyrolysis or oxidation conditions of aliphatic, linear chain diesters [19, 20]. Such compounds can be successfully applied as low volatile compounds to many practical applications, especially as aroma compounds which are widely used in cosmetic, perfumery, and food industries as a flavor and fragrance components [19-23].

According to literature survey, among the aromatic esters the most valuable and important fragrance and flavor substances are the monoesters which are obtained during esterification process of aromatic alcohols e.g., benzyl alcohol, 2-phenylethyl alcohol, 1-phenylethyl alcohol, 3-phenylpropanol, 1-phenyl-2-methyl-2-propanol, or cinnamic alcohol with the suitable aliphatic monoacid or acid anhydride [24-27]. However, rare information is available on the preparation and thermal characterization of cycloaromatic diesters derivatives of 3-phenylprop-2-en-1-ol. The main objective of the present paper is to study the thermal stability and the degradation mechanism of aromatic and cyclo-aromatic diesters derivatives of naturally 
occurring alcohol: 3-phenylprop-2-en-1-ol. The information regarding the thermal stability and degradation mechanism of those compounds can help to evaluate their possible practical applications. Due to the pleasant, balsamic odor they can find their place as flavor and fragrance ingredients added to many products, e.g., for polymers, plastics, and their commercial products particularly manufactured at high-temperature processing.

\section{Experimental}

Materials

3-Phenylprop-2-en-1-ol (98\%) was from Fluka. Phthalic anhydride (98\%), cyclohexane-1,2-dicarboxylic anhydride (98\%), 4-cyclohexene-1,2-dicarboxylic anhydride (98\%) and bicyclo[2.2.1]-5-heptene-2,3-dicarboxylic anhydride (97\%) were delivered by Merck. Butylstannoic acid was obtained from Arkema Inc., USA. The reagents were used as received.

\section{Synthesis of esters}

The unsaturated, cyclo-aromatic diesters were obtained during esterification reaction of 3-phenylprop-2-en-1-ol with cycloaliphatic acid anhydrides in the free-solvent medium. The concentration of reagents was constant. The concentration of 3-phenylprop-2-en-1-ol was $2.04 \mathrm{~mol} \mathrm{dm}^{-3}$, the concentration of an acid anhydride was $1.02 \mathrm{~mol} \mathrm{dm}^{-3}$, respectively. The reaction was carried out in the presence of butylstannoic acid as a catalyst $(0.1$ mass $\%)$. The reaction temperature was continuously increased from 135 to $155^{\circ} \mathrm{C}$ as the progress of the reaction increased. The progress of the esterification process was measured by the determination of the residual acid content. Acid number $(\mathrm{mgKOH} / \mathrm{g})$ was evaluated by titration of the sample against potassium hydroxide using phenolphthalein as an indicator and acetone as a solvent. The drop of an acid number below value $5 \mathrm{mgKOH} / \mathrm{g}$ was the indication of the process completion. The scheme of the synthesis of cyclo-aromatic diesters is presented in Fig. 1. Their structure was confirmed based on spectroscopic methods (NMR and ATR-FTIR analyses).

\section{Characterization}

${ }^{1} \mathrm{H}-\mathrm{NMR}$ spectra were obtained using an NMR BruckerAvance $300 \mathrm{MSL}$ (Germany) spectrometer at $300 \mathrm{MHz}$. The $\mathrm{CDCl}_{3}$ was used as the solvent. The TMS was applied as an internal standard. ${ }^{1} \mathrm{H}$ NMR chemical shifts in parts per million (ppm) were reported downfield from $0.00 \mathrm{ppm}$ with the use of TMS.

${ }^{13} \mathrm{CNMR}$ spectra were gathered on a Brucker 300MSL instrument (Germany). Chemical shifts were referred to chloroform serving as an internal standard.

ATR-FTIR spectra were recorded on a Tensor 27 Bruker (Germany) spectrometer equipped with diamond crystal. The spectra were recorded in the spectral range of $600-4,000 \mathrm{~cm}^{-1}$ with a resolution of $4 \mathrm{~cm}^{-1}$ and 16 scans.

Elemental analysis was made using a Perkin Elmer CHN 2400 analyser (USA)

Viscosity at $25{ }^{\circ} \mathrm{C}$ was estimated using rotating spindle rheometer, Brookfield, model DV-III (Germany).

Density at $23{ }^{\circ} \mathrm{C}$ was measured with the use of a glass pycnometer with capillary fuse Gay/Lussac $(25 \mathrm{~mL})$.

Refractive index was determined by the use of refractometer Carl Zeis Jena at $23{ }^{\circ} \mathrm{C}$.

\section{Thermal studies}

Differential scanning calorimetry analysis was performed with the use of a DSC 204 calorimeter, Netzsch (Germany). All DSC measurements were carried out in $\mathrm{Al}$ pans with pierced lid. As a reference empty Al crucible was applied. The mass of the sample was about $10 \mathrm{mg}$. The dynamic scans were performed at a heating rate of $10{ }^{\circ} \mathrm{C}$ $\mathrm{min}^{-1}$ from 20 to $500{ }^{\circ} \mathrm{C}$ under argon atmosphere $\left(20 \mathrm{~mL} \min ^{-1}\right)$.

Thermal analysis was carried out on a STA 449 Jupiter F1, Netzsch (Germany). All measurements were made in $\mathrm{Al}_{2} \mathrm{O}_{3}$ crucibles. As a reference empty $\mathrm{Al}_{2} \mathrm{O}_{3}$ crucible was applied. Dynamic scans were performed at a heating rate of $10{ }^{\circ} \mathrm{C} \min ^{-1}$ under helium atmosphere $\left(40 \mathrm{~mL} \mathrm{~min}^{-1}\right)$ from 40 to $700{ }^{\circ} \mathrm{C}$. The sample weight was about $10 \mathrm{mg}$.

The gas composition evolved during heating process was analyzed by FT IR spectrometer Brucker TGA 585
Fig. 1 The scheme of the esterification process

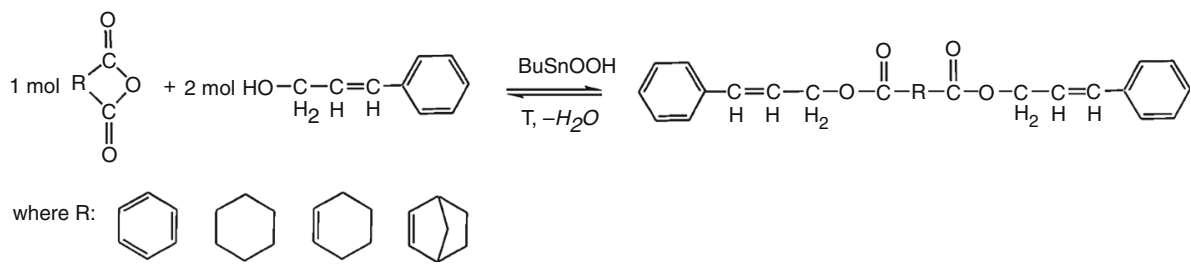


(Germany) coupling on-line to STA instrument. The FTIR spectrometer with IR cell maintained at $200{ }^{\circ} \mathrm{C}$ was connected on-line to STA instrument by a Teflon transfer line with diameter of $2 \mathrm{~mm}$ heated to $200{ }^{\circ} \mathrm{C}$. The FTIR spectra were recorded in the spectral range of $600-4,000 \mathrm{~cm}^{-1}$ with a resolution of $4 \mathrm{~cm}^{-1}$ and 16 scans per spectrum.

\section{Results and discussion}

\section{Characterization}

The structures of the four new compounds are shown in Fig. 2. As it is visible the esters differ in their structure. They contain various acid units such as aromatic (1), cyclohexane (2), cyclohexene (3), or bicyclo (4) rings. Chemical structures of prepared esters were confirmed by elemental analysis, Table 1 and spectroscopic methods. The ATR-FTIR

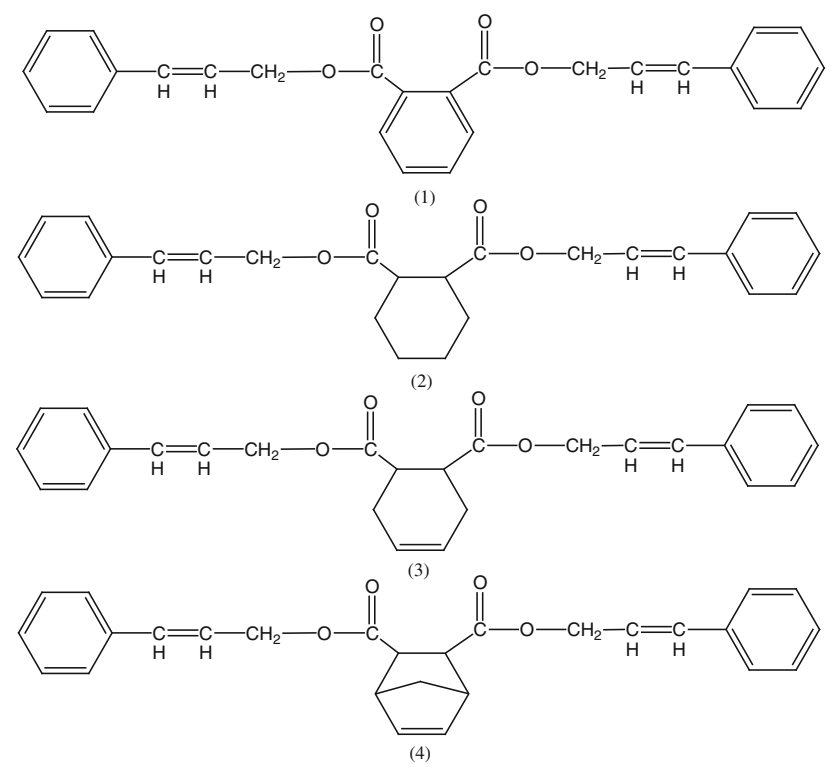

Fig. 2 The structure of the unsaturated (cyclo)-aromatic diesters

Table 1 Elemental analysis of newly obtained compounds

\begin{tabular}{lllll}
\hline Compound & Formula & $M / \mathrm{g} \mathrm{mol}^{-1}$ & \multicolumn{2}{c}{$w_{i}$ calc./\% $w_{i}$ found $\%$} \\
\cline { 3 - 5 } & & & $\mathrm{C}$ & $\mathrm{H}$ \\
\hline 1 & $\mathrm{C}_{26} \mathrm{H}_{22} \mathrm{O}_{4}$ & 398.46 & 78.37 & 5.56 \\
& & & 78.33 & 5.50 \\
& & & 77.20 & 6.98 \\
3 & $\mathrm{C}_{26} \mathrm{H}_{28} \mathrm{O}_{4}$ & 404.51 & 77.16 & 6.95 \\
& & & 77.59 & 6.51 \\
& & & & \\
4 & $\mathrm{C}_{26} \mathrm{H}_{26} \mathrm{O}_{4}$ & 402.49 & 77.52 & 6.45 \\
& & & 78.24 & 6.32 \\
& $\mathrm{C}_{27} \mathrm{H}_{26} \mathrm{O}_{4}$ & 414.50 & 78.19 & 6.23 \\
\hline
\end{tabular}

spectra of the novel esters are shown in Fig. 3. The signals characteristic for aromatic skeletal absorption are clearly visible. The vibrations at $3,027-3,081 \mathrm{~cm}^{-1}$ which describes the stretching vibrations $(v)$ of $\mathrm{C}_{\mathrm{Ar}}-\mathrm{H}$ groups, two signals at $1,448-1,494 \mathrm{~cm}^{-1}$ and at $1,577-1,598 \mathrm{~cm}^{-1}$ connecting with the stretching vibrations $(v)$ of $\mathrm{C}=\mathrm{C}$ in phenyl ring and very intensive bands in the range of $650-900 \mathrm{~cm}^{-1}$ responsible for out-of-plane deformation vibrations $(\delta)$ of $\mathrm{C}_{\mathrm{Ar}}-\mathrm{H}$ groups are observed. The signals of the stretching vibrations (v) of non-aromatic $\mathrm{C}=\mathrm{C}$ groups are found at $1,665 \mathrm{~cm}^{-1}$ as a small band. Another characteristic absorption bands for alkenes such as the stretching vibrations $(v)$ of $=\mathrm{C}-\mathrm{H}$ groups as well as the out-of-plane deformation vibrations $(\delta)$ of $=\mathrm{C}-\mathrm{H}$ groups at $-\mathrm{CH}=\mathrm{CH}-$ are overlapping with those characteristic for phenyl ring and thus they are visible in the almost same spectral range. The signals from the aliphatic units are present in the range of 2,849-2,935 $\mathrm{cm}^{-1}$ (stretching vibrations $v$ of $\mathrm{C}-\mathrm{H}$ ) and at $1,448 \mathrm{~cm}^{-1}$ (deformation vibrations $\delta$ of $\mathrm{C}-\mathrm{H}$ in $-\mathrm{CH}_{2}-$ groups) which are partially overlapped with those characteristic for aromatic units. A very intensive absorption peak of the carbonyl group $(v \mathrm{C}=\mathrm{O})$ in $\alpha, \beta$-unsaturated, aromatic esters is present at $1,720-1,725 \mathrm{~cm}^{-1}$. The lines visible at $1,126-1,176 \mathrm{~cm}^{-1}$ and the lines at $1,016-1,070 \mathrm{~cm}^{-1}$ are the result of the stretching vibrations $(v)$ of $\mathrm{C}-\mathrm{O}$ groups in esters. Also, the signals in the range of $1,350-1,385 \mathrm{~cm}^{-1}$ characteristic for deformation vibration $(\delta)$ of $\mathrm{C}-\mathrm{H}$ for ester compounds appear on the spectrum. The presence of bands at $964 \mathrm{~cm}^{-1}$ is directly connected with the skeletal vibrations of $\mathrm{C}-\mathrm{C}$ for cycloalkane and cycloalkene functional groups or out-ofplane deformation vibrations $(\delta)$ of $=\mathrm{C}-\mathrm{H}$ for $-\mathrm{CH}=\mathrm{CH}-$ groups. The lack of the absorption bands responsible for the stretching vibrations $(v)$ of $-\mathrm{OH}$ groups at $3,265 \mathrm{~cm}^{-1}[28]$ is the indication that the esterification process was successful and allowed obtaining the compounds which are not previously described in the literature data.

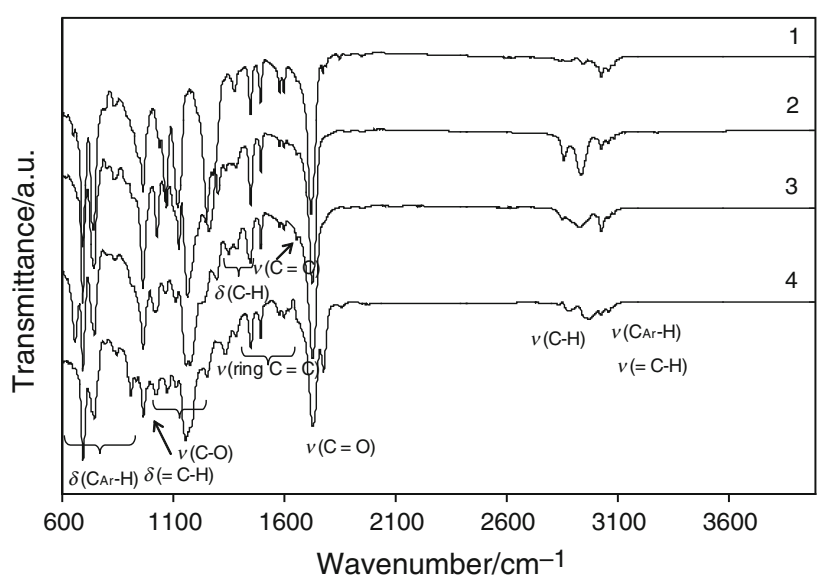

Fig. 3 ATR-FTIR spectra of newly obtained compounds 

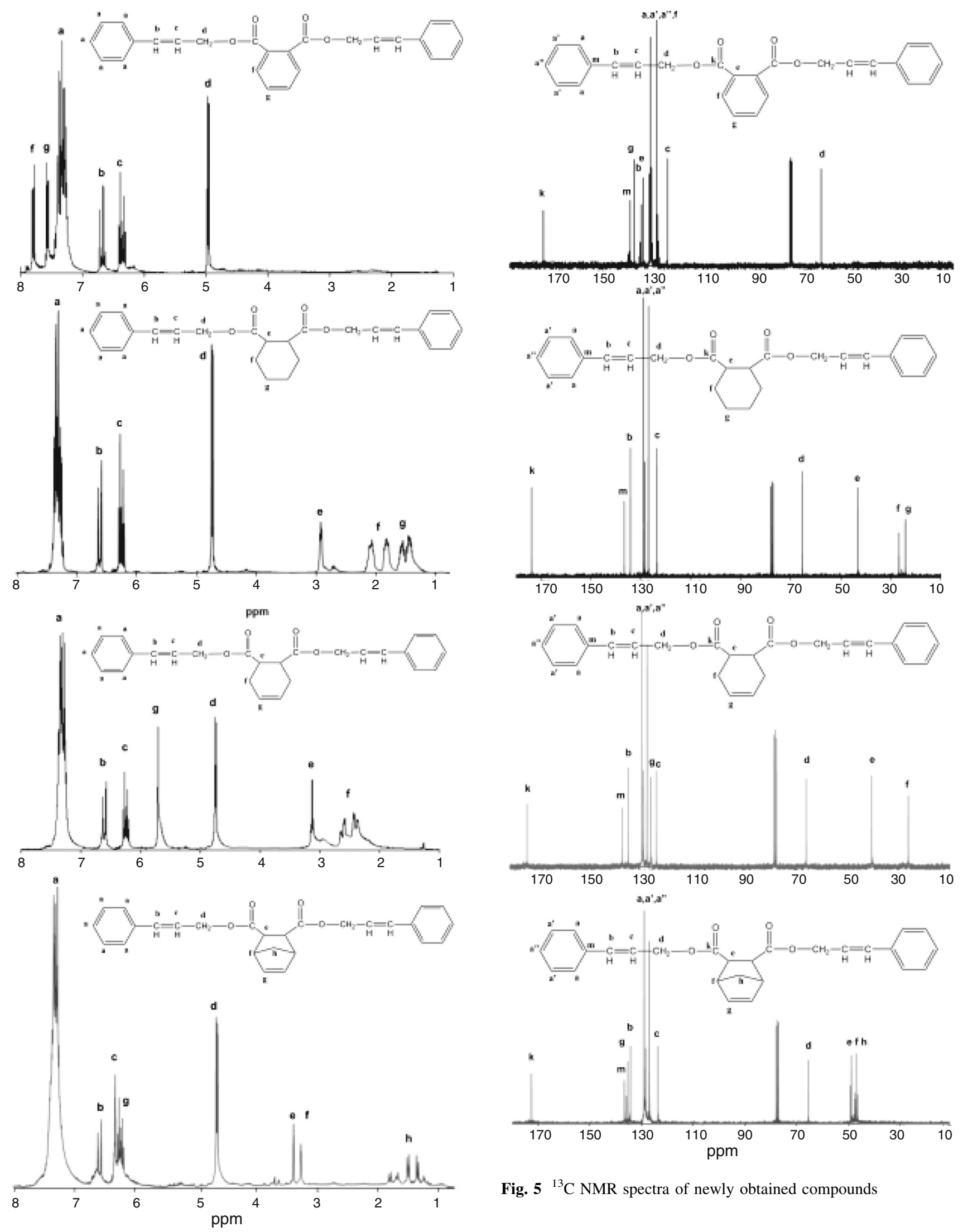

Fig. $5{ }^{13} \mathrm{C}$ NMR spectra of newly obtained compounds

Fig. $4{ }^{1} \mathrm{H}$ NMR spectra of newly obtained compounds 
Table 2 Properties of newly obtained compounds

\begin{tabular}{lllll}
\hline Compound & Viscosity/m Pas & Density/g dm & $n_{\mathrm{D}}^{20}$ & $T_{\text {boil }}{ }^{\circ} \mathrm{C}$ \\
\hline 1 & 885 & 1.212 & 1.4955 & 220 \\
2 & 725 & 1.156 & 1.4870 & 200 \\
3 & 890 & 1.179 & 1.4920 & 215 \\
4 & 950 & 1.225 & 1.4910 & 210 \\
\hline
\end{tabular}

Figures 4 and 5 show the ${ }^{1} \mathrm{H}$ and ${ }^{13} \mathrm{C}$ NMR spectra of novel compounds, respectively. The resonance signals responsible for the protons at aromatic rings in the range of $\delta=7.20-7.90 \mathrm{ppm}$ are observed. The resonance signals characteristic for the protons assigned to carbon-carbon double bonds: $\delta=6.30-6.40 \mathrm{ppm}$ and $\delta=6.55-6.65 \mathrm{ppm}$ are present. The signals at $\delta=4.75 \mathrm{ppm}$ are characteristic for methylene groups in esters. In addition, for compound number 2 , the protons attached to cyclohexane rings at $2.90 \mathrm{ppm}$ (protons near carbonyl groups), at $1.80-2.10 \mathrm{ppm}$, and $1.40-1.50 \mathrm{ppm}$ are clearly visible. The protons in surroundings of carbon-carbon double bonds in cyclohexene ring are observed at $5.70 \mathrm{ppm}$ for compound number 3 . The other protons in cyclohexene ring are appeared at $3.10 \mathrm{ppm}$ (protons near carbonyl groups) and at 2.30-2.40 ppm and $2.60-2.70 \mathrm{ppm}$. In the case of compound number 4 , the protons in surroundings of carbon-carbon double bonds in bicyclo ring are appeared at $6.30 \mathrm{ppm}$ and they are partially covered with those characteristic for carbon-carbon double bonds in the side chain. The other protons in bicyclo ring are visible at 3.15-3.30 ppm, 1.60-1.80, and 1.30-1.50 ppm. In addition, the absence of resonance signals characteristic for methylene protons in 3-phenylprop-2-en-1-ol at $4.30 \mathrm{ppm}$ confirms the formation of desired products.

The all resonance signals responsible for the carbons in the structure of those compounds are marked in Fig. 5. In addition, the absence of the signals for carbon in $-\mathrm{CH}_{2}-$ group of 3-phenylprop-2-en-1-ol (at $64 \mathrm{ppm}$ ) and the
Table 3 DSC data of cyclo-aromatic diesters

\begin{tabular}{llll}
\hline diester & $T_{\text {onset }} /{ }^{\circ} \mathrm{C}$ & $T_{\text {peak (exo) }} /{ }^{\circ} \mathrm{C}$ & $T_{\text {peak (endo) }} /{ }^{\circ} \mathrm{C}$ \\
\hline 1 & 280 & 324 & $355 / 395$ \\
2 & 272 & 320 & $346 / 393$ \\
3 & 263 & 302 & $319 / 383$ \\
4 & 244 & 292 & $331 / 396$ \\
\hline
\end{tabular}

presence of new signals at $67 \mathrm{ppm}$ (carbons in $-\mathrm{CH}_{2}-$ groups) and at $175 \mathrm{ppm}$ (carbons in carbonyl groups) confirms the formation of ester products.

The newly obtained compounds are viscous liquids with balsamic odor and boiling temperatures ranges from 200 to $220{ }^{\circ} \mathrm{C}$. Their physical properties are placed in Table 2.

Thermal studies

Figure 6 shows the DSC curves of newly obtained compounds. In addition, the DSC data are placed in Table 3. The first DSC signal is exothermic. It appears at temperature over $240{ }^{\circ} \mathrm{C}$ with onset temperature $\left(T_{\text {onset }}\right)$ and peak maximum temperature $\left(T_{\text {peak (exo) }}\right)$ given in Table 3 . The presence of this signal was unexpected because DSC analysis was performed in inert atmosphere. Due to this the decomposition of those compounds should be described by endothermic process. The exothermic signal on DSC curves is connected with the chemical reactions happened during heating of studied compounds. Probably, it is a result of the polymerization process in a gaseous phase of decomposition products formed during heating of studied compounds. This peak is followed by non-well separated endothermic signals with peak maximum temperature $\left(T_{\text {peak (endo) }}\right)$, Table 3 . The presence of those endothermic signals is connected with the main decomposition step of studied compounds.
Fig. 6 DSC curves of newly obtained compounds

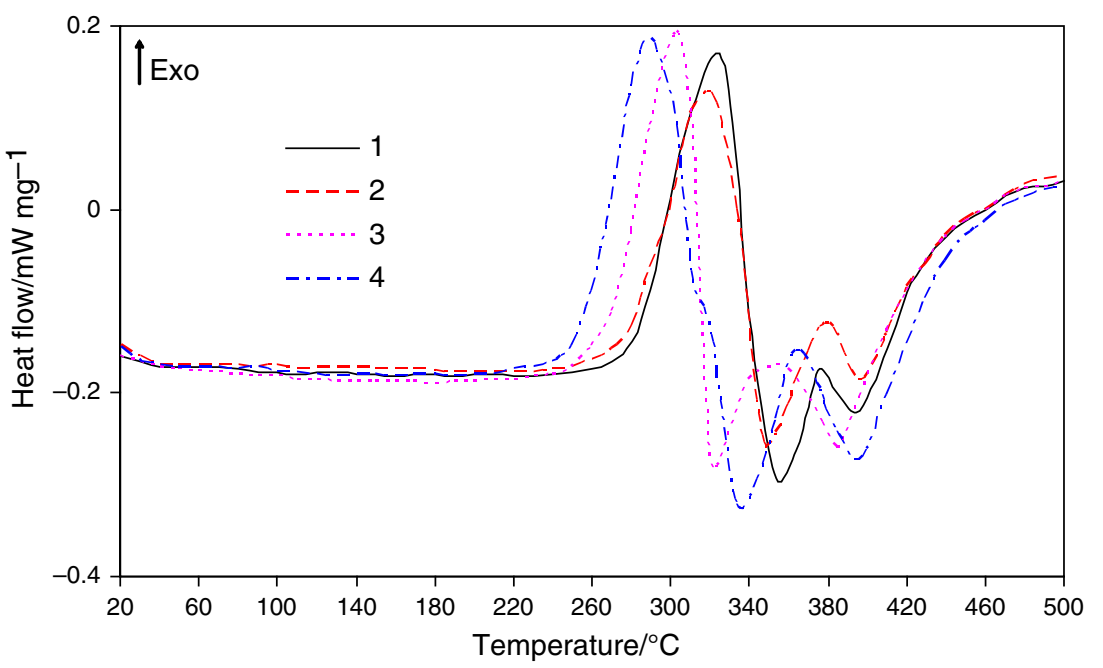


Fig. 7 TG and DTG curves of newly obtained compounds
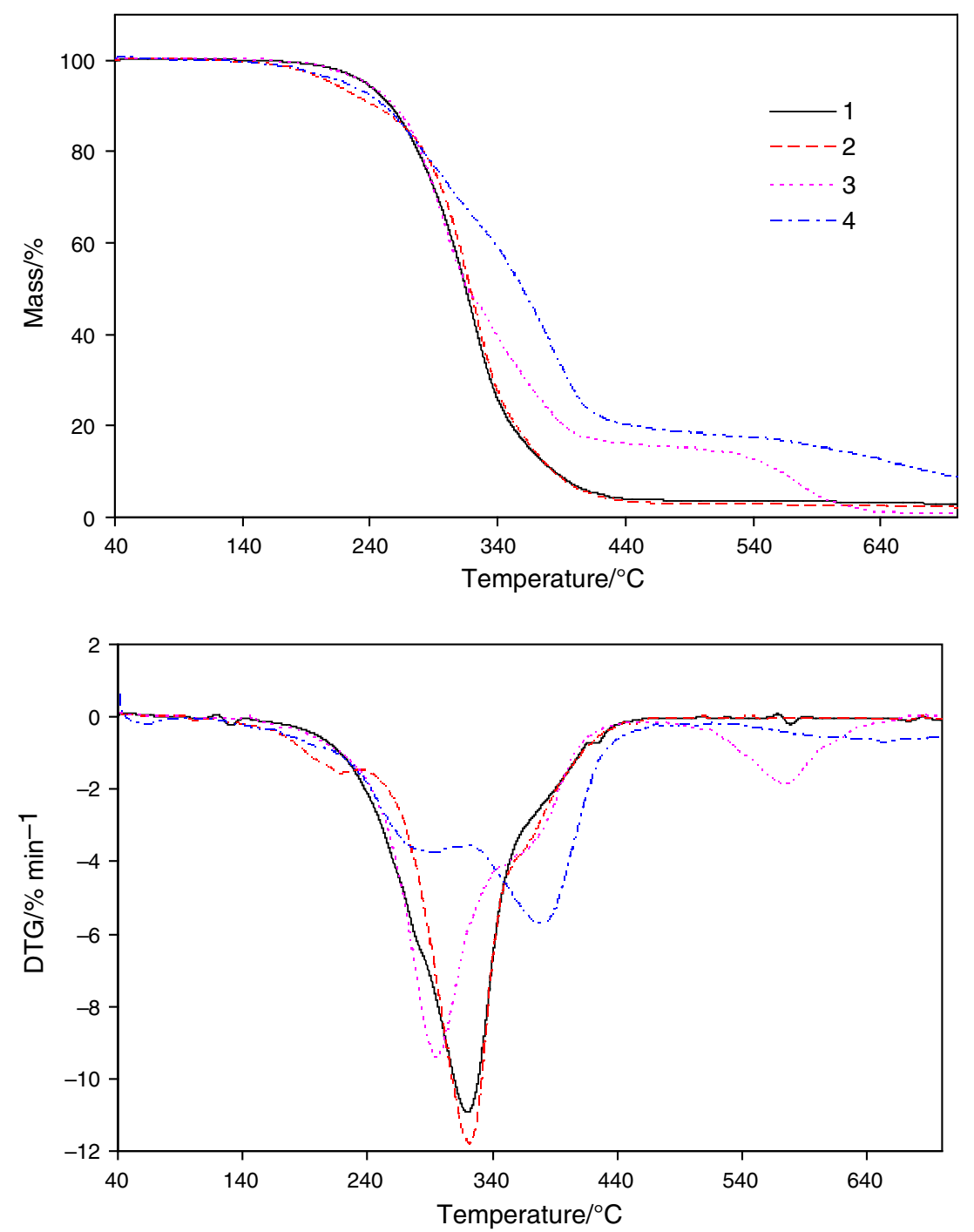

The TG and DTG curves are presented in Fig. 7. In addition, the characteristic data obtained from TG/DTG curves are placed in Table 4. The newly obtained cycloaromatic diesters are compounds with high thermal stability. The initial decomposition temperature determined at $5 \%$ of mass loss (IDT) was higher than $200{ }^{\circ} \mathrm{C}$, Table 4.

In addition, the changes in the degradation path of studied compounds are observed from TG/DTG results. The compound containing phthalic unit (number 1) and compound containing cyclohexane unit (number 2) in the structure decompose in one main step. This decomposition step is appeared as a one non-well separated signal in DTG curves. It occurred from c.a. $200{ }^{\circ} \mathrm{C}$ up to temperatures over $450{ }^{\circ} \mathrm{C}$ with the significant mass loss above $97 \%$ for compound 1 and above $98 \%$ for compound 2 . However, the decomposition of the compound containing cyclohexene unit (number 3 ) and compound containing nadic unit (number 4) in the structure run through two main steps. The first, non-well separated step is visible from IDT to almost
$480{ }^{\circ} \mathrm{C}$ with the mass loss over $84 \%$ for compound 3 and over $82 \%$ for compound 4 . The second decomposition step is observed at considerably higher temperatures (over $480{ }^{\circ} \mathrm{C}$ ) with $T_{\max 2} 574{ }^{\circ} \mathrm{C}$ for compound number 3 and $654{ }^{\circ} \mathrm{C}$ for compound number 4 with the mass loss $14.85 \%$ (compound 3 ) and $8.56 \%$ (compound 4 ). The presence of this signal is not detected for compound containing phthalic and compound containing cycloalkane units (number 1 and 2).

The analysis of the gaseous products emitted during pyrolysis of studied esters indicates on the similar mechanism of their decomposition at the first step. The FTIR spectra of the gases evolved during the first step of decomposition are gathered at three different temperatures (as three scans), Fig. 8. The first FTIR spectrum was gathered for temperature, where $20 \%$ of mass loss $\left(T_{20} \%\right)$ was observed (first scan-a). The second FTIR spectrum was collected where first peak maximum temperature $\left(T_{\max 1}\right)$ on DTG curves was visible (second scan-b). The 
Table 4 TG-DTG data of cyclo-aromatic diesters

\begin{tabular}{|c|c|c|c|c|c|c|c|c|c|}
\hline diester & $I D T /{ }^{\circ} \mathrm{C}$ & $T_{10 \%} \%{ }^{\circ} \mathrm{C}$ & $T_{20} \% /{ }^{\circ} \mathrm{C}$ & $T_{50 \%} /{ }^{\circ} \mathrm{C}$ & $T_{\max 1} / T_{\max 1^{\prime}} /{ }^{\circ} \mathrm{C}$ & $W_{\text {loss } 1} 1 \%$ & $T_{\max 2} /{ }^{\circ} \mathrm{C}$ & $W_{\text {loss } 2} / \%$ & $\mathrm{RM} / \%$ \\
\hline 1 & 237 & 256 & 278 & 315 & $320 / 376$ & 97.09 & - & - & 2.91 \\
\hline 2 & 209 & 243 & 282 & 318 & $321 / 375$ & 98.04 & - & - & 1.96 \\
\hline 3 & 236 & 259 & 279 & 316 & $295 / 373$ & 84.40 & 574 & 14.85 & 0.75 \\
\hline 4 & 220 & 251 & 281 & 359 & $293 / 380$ & 82.90 & 654 & 8.56 & 8.54 \\
\hline
\end{tabular}

$R M$-residual mass at $700^{\circ} \mathrm{C}$

$W_{\text {loss }}$-mass loss

Fig. 8 FTIR spectra of the gaseous products evolved during the first decomposition step, the spectra gathered at $a-T_{20} \%, b$-at $T_{\max 1}$, $c$-at $T_{\max 1^{\prime}}$
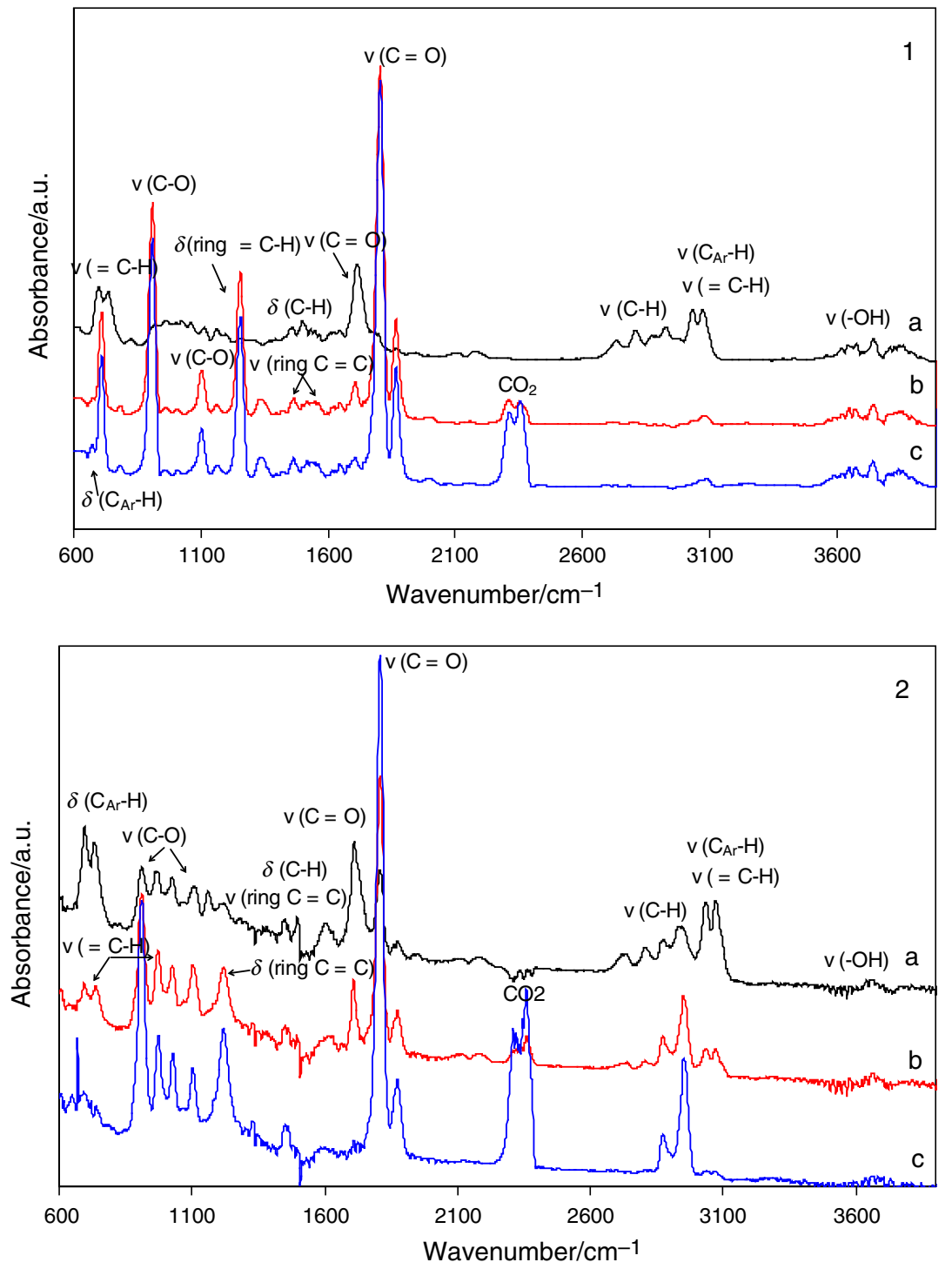

third FTIR spectrum was obtained for temperature c.a. $373-380{ }^{\circ} \mathrm{C}$ where the hump on the first DTG signal was indicated. This temperature was marked as $T_{\max 1^{\prime}}$ (third scan-c), Table 4.

The FTIR spectra for all four cyclo-aromatic compounds exhibited bands characteristic for carbon dioxide at $670 \mathrm{~cm}^{-1}$ and $2,310-2,358 \mathrm{~cm}^{-1}$, carbon monooxide at
2,182 and $2,110 \mathrm{~cm}^{-1}$ and water or acids (the region of $3,600-3,700 \mathrm{~cm}^{-1}$ ) [29-32].

In addition, for all studied compounds, the bands attributed to the aliphatic fragments (stretching vibrations of $\mathrm{C}-\mathrm{H}$ in $-\mathrm{CH}_{2}-$ groups) at $2,860-2,923 \mathrm{~cm}^{-1}$ are observed. The presence of the stretching vibrations of $=\mathrm{C}-$ $\mathrm{H}$ and out-of-plane deformation vibrations of $=\mathrm{C}-\mathrm{H}$ groups 
Fig. 8 continued
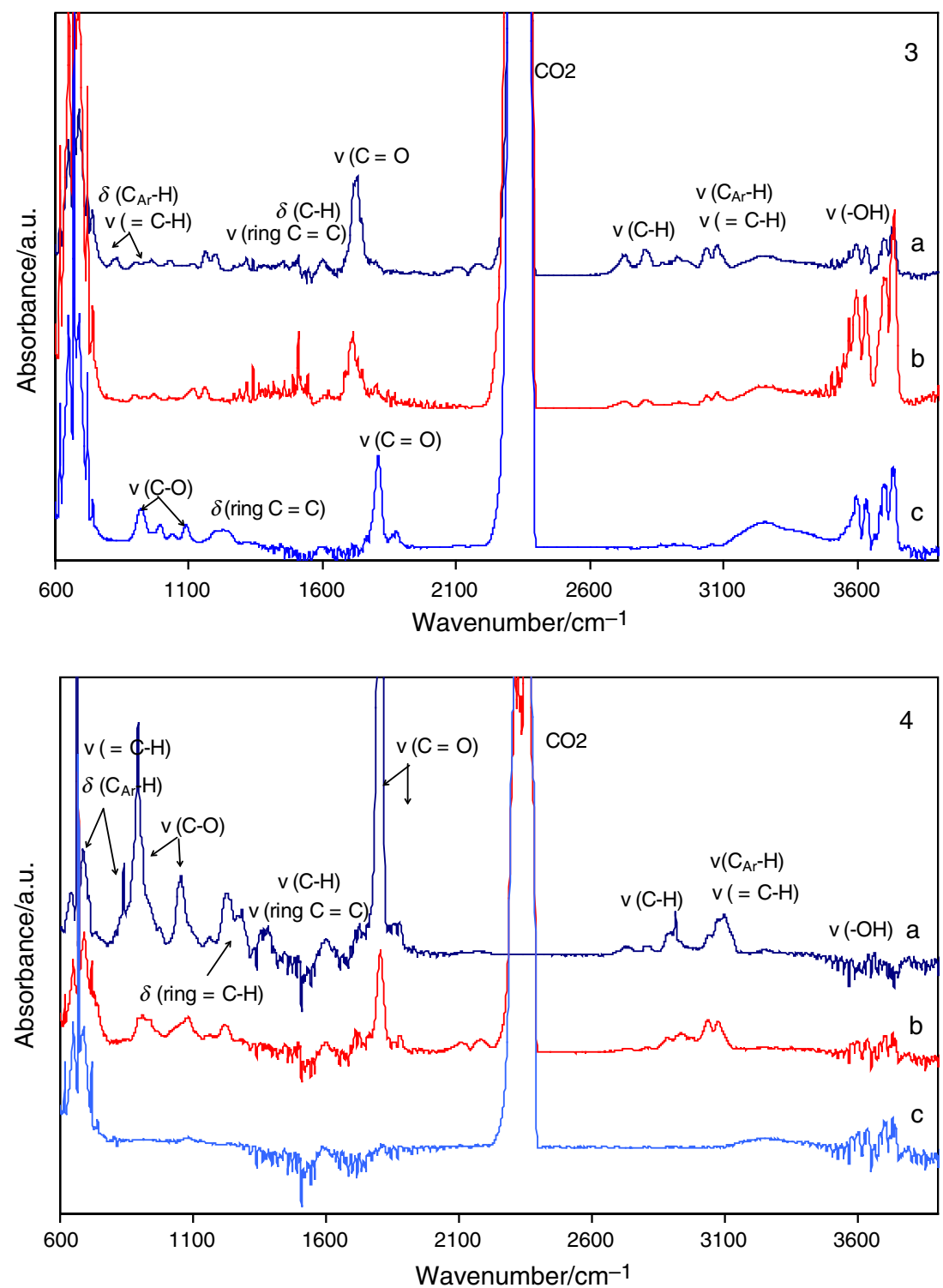

which appears as bands in the region of 660-900 $\mathrm{cm}^{-1}$ and as two bands at 3,029 and at $3,081 \mathrm{~cm}^{-1}$ characteristic for alkene is indicated. The absorption signals at $3,029-3,081 \mathrm{~cm}^{-1}$ and at $660-900 \mathrm{~cm}^{-1}$ may also be the result of the stretching vibrations of $\mathrm{C}_{\mathrm{Ar}}-\mathrm{H}$ and out-ofplane deformation vibrations of $\mathrm{C}_{\mathrm{Ar}}-\mathrm{H}$. The presence of the stretching vibrations of $\mathrm{C}=\mathrm{C}$ in phenyl rings at $1,440-1,598 \mathrm{~cm}^{-1}$ and in-plane deformation vibrations of aromatic $=\mathrm{C}-\mathrm{H}$ groups for monosubstituted benzenes at 1,146-1,200 $\mathrm{cm}^{-1}$ also indicates the formation of aromatic compounds over the gases emitted during the first decomposition step.

At $T_{20} \%$ and $T_{\max 1}$, the presence of the absorption bands at $1,708 \mathrm{~cm}^{-1}$ (compound 1 and compound 2) at 1,727 $\mathrm{cm}^{-1}$ (compound 3) and at $1,722 \mathrm{~cm}^{-1}$ (compound 4) characteristic for the stretching vibrations of $\mathrm{C}=\mathrm{O}$ groups is observed. The appearance of the peak in the carbonyl region and the bands at 2,710 and at $2,820 \mathrm{~cm}^{-1}$ (stretching vibrations of $\mathrm{C}-\mathrm{H}$ in $\mathrm{O}=\mathrm{C}-\mathrm{H}$ groups) and stretching vibration of $\mathrm{C}-\mathrm{O}$ bond at $1,146 \mathrm{~cm}^{-1}$ may indicate on the formation of aldehyde fragments during decomposition of all cyclo-aromatic compounds. In addition, the presence of two bands at 1,806 and 1,860 $\mathrm{cm}^{-1}$ (compound 1 and compound 2), at 1,805 and $1,862 \mathrm{~cm}^{-1}$ (compound 3 ) and at 1,803 and $1,847 \mathrm{~cm}^{-1}$ (compound 4) responsible for the stretching vibrations of $\mathrm{C}=\mathrm{O}$ groups and at $912,1,050-1,300 \mathrm{~cm}^{-1}$ (stretching vibrations of $\mathrm{C}-\mathrm{O}-\mathrm{C}$ ) suggests the formation of an acid anhydride during decomposition process of newly obtained cyclo-aromatic compounds. The FTIR data clearly indicated that the mixture of various gaseous products was 
Scheme 1 The scheme of pyrolysis of studied compounds

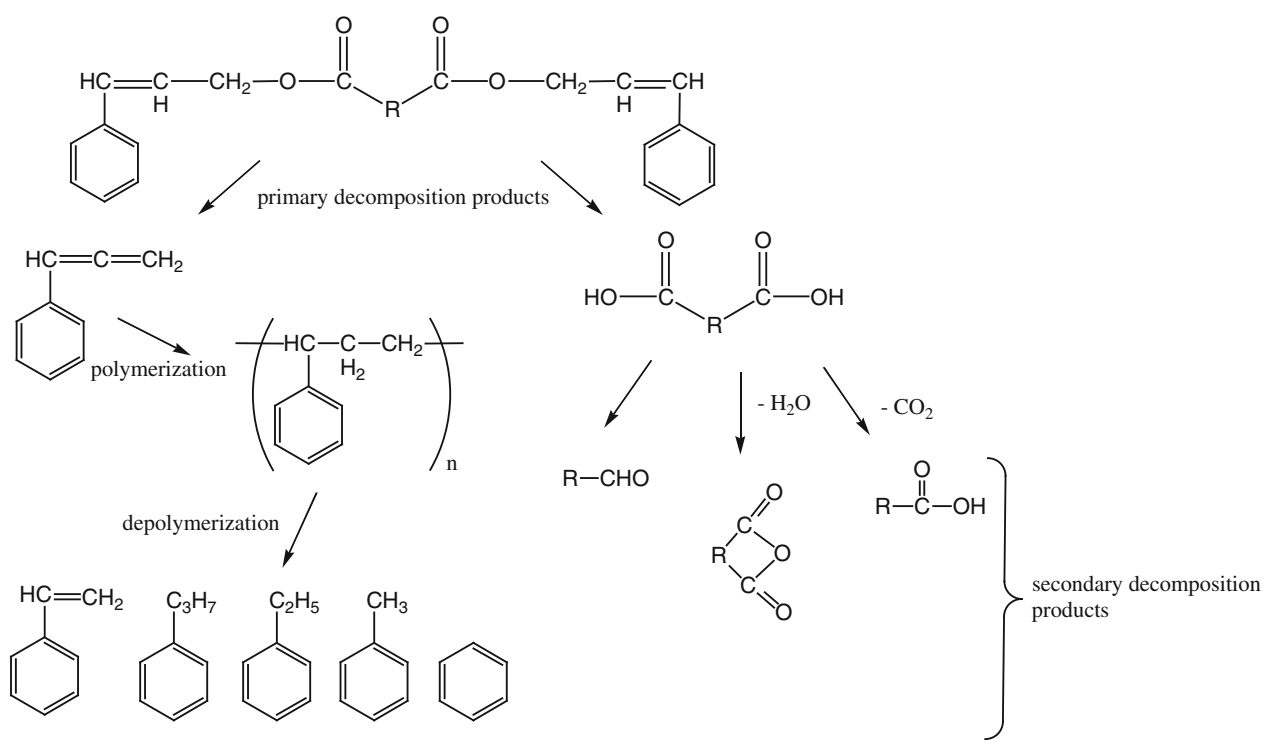

Fig. 9 FTIR spectra of the gaseous products evolved during the second decomposition step $\left(T_{\max 2}\right)$

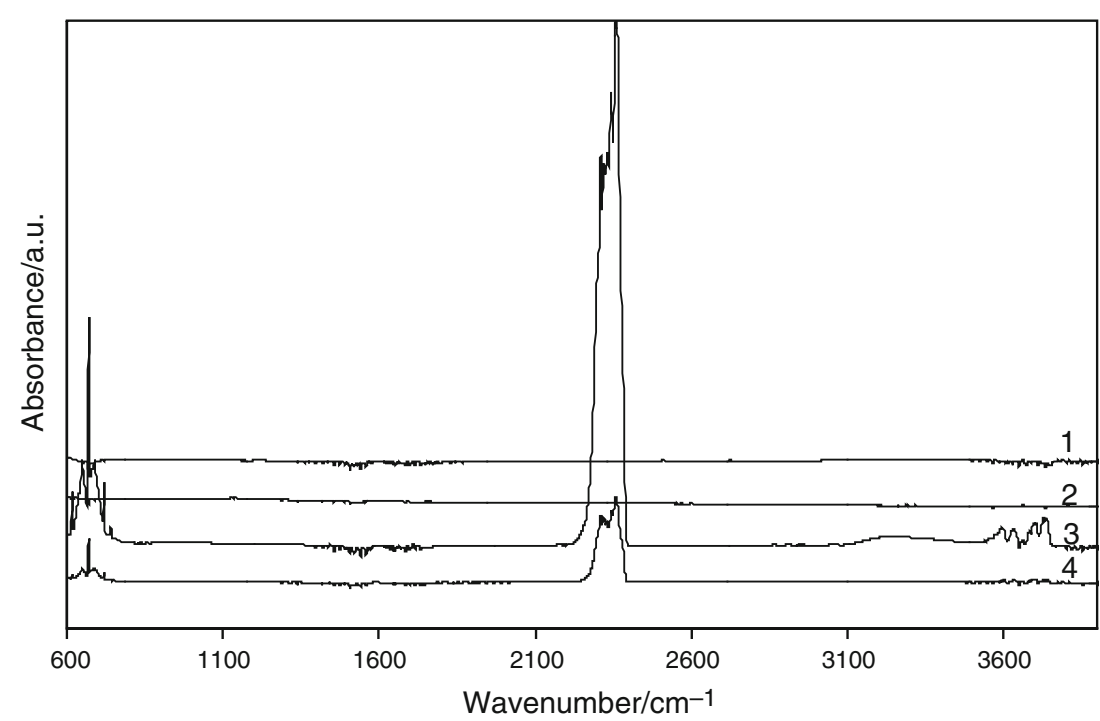

evolved during the first decomposition step of studied compounds. Those results suggest that in the temperature range $T_{20} \%-T_{\max 1^{\prime}}$ as main decomposition products alkene, aromatic, aldehyde, acid and cyclic anhydride fragments are emitted. The results indicate mainly on the $c i s$ eliminations reaction of diesters during their pyrolysis. It is in accordance with the literature data. Generally, the heating of esters with $\beta$-hydrogen causes the cleavage of their bonds and the formation of corresponding alkene and acid fragments [33-35]. However, the emission of carbon dioxide and water indicates also on the partial decarboxylation process of dicarboxylic acids and the formation of corresponding monoacids as well as on the additional condensation reactions of carboxyl groups which can cause the production of acid anhydrides or aldehyde fragments, Scheme 1.
The FTIR spectra of gases evolved during the second decomposition step for all studied compounds are presented in Fig. 9. The spectra confirm that compound containing phthalic unit and compound containing cyclohexane unit (compound 1 and compound 2) in the structure decompose in only one step. At higher temperatures no gases are emitted. However, the FTIR spectra gathered at second peak maximum temperature $\left(T_{\max 2}\right)$ for compound containing tetrahydrophthalic unit and compound containing nadic unit in the structure are demonstrated only the emission of carbon dioxide and water vapor during the second decomposition step. The existence of the vibrations for carbon dioxide (670 and 2,310-2,358 $\left.\mathrm{cm}^{-1}\right)$ and water $\left(3,600-3,700 \mathrm{~cm}^{-1}\right)$ is detected. It indicates on the carbonization process of the residue formed after the first decomposition step. In addition, the higher residual mass 
$(8.54 \%)$ at the temperature of $700{ }^{\circ} \mathrm{C}$ for compound 4 comparing to other studied compounds is observed, Table 4. Probably, the residue formed after the first decomposition step of compound 4 is more resistant to the carbonization process than residue formed from other compounds. Thus, the carbonization process runs slowly and requires higher temperatures to obtain the total carbonization of the residue formed from compound 4.

\section{Conclusions}

TG studies proved that the prepared compounds are characterized by high thermal stability with initial decomposition temperature higher than $200{ }^{\circ} \mathrm{C}$. Dependent on the structure of cyclo-aromatic compounds their thermal decomposition in inert atmosphere run as one or two non-separated steps visible as the peaks in $T_{\max 1}$ and $T_{\max 2}$ on DTG curves. The formation of various compounds during pyrolysis was confirmed by TG/FTIR. The emission of carbon dioxide, carbon monooxide, water vapor, alkene, aromatic, aldehyde, acids, and cyclic anhydrides fragments indicated mainly on the cis elimination reactions, partial decarboxylation, and condensation process of carboxyl groups of primary formed decomposition products during pyrolysis.

Open Access This article is distributed under the terms of the Creative Commons Attribution License which permits any use, distribution, and reproduction in any medium, provided the original author(s) and the source are credited.

\section{References}

1. Homzová K, Győryová K, Bujdošová Z, Hudecová D, Ganajová M, Vargová Z, Kovářová J. Synthesis, thermal, spectral and biological properties of zinc(II) 4-hydroxybenzoate complexes. J Therm Anal Calorim. 2014;. doi:10.1007/s10973-014-3702-x.

2. Febrero L, Granada E, Pérez C, Patiño D, Arce E. Characterisation and comparison of biomass ashes with different thermal histories using TG-DSC. J Therm Anal Calorim. 2014;. doi:10. 1007/s10973-014-3717-3.

3. Alves APM, Araujo AS, Bezerra FA, Sousa KS, Lima SJG, Fonseca MG. Kinetics of dehydration and textural characterizations of selectively leached vermiculites. J Therm Anal Calorim. 2014;. doi:10.1007/s10973-014-3692-8.

4. Simplício S, Fernandes Lucas E, da Silva Antonio, Costa M, Cunha Costa L, de Santa Claudio, Maria L. Thermal resistance of magnetic polymeric composites based on styrene, divinylbenzene, and $\mathrm{Ni}$ and Co particles. J Therm Anal Calorim. 2014; doi:10.1007/s10973-014-3703-9.

5. Soares Maria, de Mendonça C, de Barros Prado, Lima I, Flávio Soares Aragão C, Paula Barreto Gomes A. Thermal compatibility between hydroquinone and retinoic acid in pharmaceutical formulations. J Therm Anal Calorim. 2014;. doi:10.1007/s10973013-2941-6.

6. Grochowicz M, Gawdzik B, Jaćkowska M, Buszewski B. Thermal characterization of polymeric anion exchangers with a dendrimeric structure. J Therm Anal Calorim. 2013;114:955-61.
7. Grochowicz M, Gawdzik B, Jaćkowska M, Buszewski B. Investigation of the thermal behavior of new silica-polymer anion exchangers. J Therm Anal Calorim. 2013;112:885-91.

8. Veselá P, Slovák V. Organic xerogels based on condensation of different $m$-substituted phenols with formaldehyde. J Therm Anal Calorim. 2014;. doi:10.1007/s10973-014-3708-4.

9. Fuliaş A, Vlase G, Şoica C, Bercean V, Vlase T, Ledeţi I. Thermal behaviour of a modified encapsulation agent. J Therm Anal Calorim. 2014;. doi:10.1007/s10973-014-3727-1.

10. Xu Q, Jin C, Jiang Y. Analysis of the relationship between MCC and thermal analysis results in evaluating flammability of EPS foam. J Therm Anal Calorim. 2014;. doi:10.1007/s10973-0143736-0.

11. Correia DM, Gámiz-González MA, Botelho G, Vidaurre A, Gomez Ribelles JL, Lanceros-Mendez S, Sencadas V. Effect of neutralization and cross-linking on the thermal degradation of chitosan electrospun membranes. J Therm Anal Calorim. 2014; doi:10.1007/s10973-014-3707-5.

12. Silva ACM, Gálico DA, Guerra RB, Legendre AO, Rinaldo D, Galhiane MS, Bannach G. Study of some volatile compounds evolved from the thermal decomposition of atenolol. J Therm Anal Calorim. 2014;115:2517-20.

13. Jiao Q-J, Zhu Y-L, Xing J-Ch, Ren H, Huang H. Thermal decomposition of RDX/AP by TG-DSC-MS-FTIR. J Therm Anal Calorim. 2014;. doi:10.1007/s10973-013-3621-2.

14. Shabanian M, Faghihi K, Raeisi A, Varvanifarahani M, Khonakdar HA, Wagenknecht U. New poly(ether-imide)/MWCNT nanocomposite. J Therm Anal Calorim. 2014;. doi:10.1007/ s10973-014-3682-x.

15. Cucos A, Budrugeac P. Simultaneous TG/DTG-DSC-FTIR characterization of collagen in inert and oxidative atmospheres. J Therm Anal Calorim. 2014;115:2079-87.

16. Gálico DA, Perpétuo GL, Castro RAE, Treu-Filho O, Legendre AO, Galhiane MS, Bannach G. Thermoanalytical study of nimesulide and their recrystallization products obtained from solutions of several alcohols. J Therm Anal Calorim. 2014;115:2385-90.

17. Lysenko EN, Surzhikov AP, Zhuravkov SP, Vlasov VA, Pustovalov AV, Yavorovsky NA. The oxidation kinetics study of ultrafine iron powders by thermogravimetric analysis. J Therm Anal Calorim. 2014;115:1447-52.

18. Ratkovic S, Peica N, Thomsen Ch, Bukur DB, Boskovic G. Thermal stability evolution of carbon nanotubes caused by liquid oxidation. J Therm Anal Calorim. 2014;115:1477-86.

19. Worzakowska M, Ścigalski P. TG/DSC/FTIR characterization of linear geranyl diesters. J Therm Anal Calorim. 2013;113:53-60.

20. Worzakowska M, Ścigalski P. Synthesis and thermal behavior of linera neryl diesters in inert and oxidative atmosphere. J Therm Anal Calorim. 2014;115:783-92.

21. Peter TR, Robert B. Beeswax through the ages. Pers Care. 2001;10:27-31.

22. Misra S, Ghosh A. In: Linskens HF, Jackson JF, editors. Analysis of epicuticular waxes. Essential oils and waxes. New York: Springer-Verlag; 1992.

23. Chatterjee T, Bhattacharyya DK. Synthesis of terpene esters by an immobilized lipase in a solvent-free system. Biotechnol Lett. 1998;20:865-8.

24. Bauer K, Garbe D, Surburg H. Common fragrance and flavor materials: preparation, properties and uses. New York: Wiley; 2001. p. 43-5.

25. Croteau R. Fragrance and flavour substances. Germany, D\&PS Verlag; 1980. p. 13.

26. Gildemeister E, Hoffmann FR. The volatile oils. New York: Wiley; 1913.

27. Armstrong DW, Gillies B, Yamazaki H. In: Charalambous G, editor. Flavor chemistry, trends and development. New York: Elsevier Science Publisher; 1989. 
28. Sokrates G. Infrared and raman characteristic group frequencies, tables and charts. New York: Wiley; 2001.

29. NIST chemistry webbook standard reference database number 69 , 2011, http://webbook.nist.gov/chemistry. Accessed 17 Mar 2014.

30. Ionashiro EY, Caires FJ, Siqueira ABS, Lima LS, Carvalho CT. Thermal behaviour of fumaric acid, sodium fumarate and its compounds with light trivalent lanthanides. J Therm Anal Calorim. 2012;108:1183-8.

31. Shi J, Wang Z, Liu Y, Wang C. Investigation of thermal behavior of enoxacin and its hydrochloride. $\mathrm{J}$ Therm Anal Calorim. 2012;108:299-306.
32. Bassilakis R, Carangelo RM, Wojtowicz MA. TG-FTIR analysis of biomass pyrolysis. Fuel. 2001;80:1765-86.

33. Bailey WJ, Barclay R Jr. Pyrolysis of esters. V. Mechanism of 1,4-elimination. J Org Chem. 1956;21:328-31.

34. Bilger EM, Hibbert H. Mechanism of organic reactions. IV. Pyrolysis of esters and acetals. J Am Oil Chem Soc. 1936;58:823-6.

35. Arnold RT, Smith GG, Dodson RM. Mechanism of the pyrolysis of esters. J Org Chem. 1950;15:1256-60. 